\title{
Diel isotopic fluctuation in surface seston and its physiological and ecological implications
}

\author{
J. Xu' ${ }^{1}$ P. Xie ${ }^{1, *}$, J. Qin ${ }^{1,2}$
}

\begin{abstract}
${ }^{1}$ Donghu Experimental Station of Lake Ecosystems, State Key Laboratory of Freshwater Ecology and Biotechnology of China, Institute of Hydrobiology, Chinese Academy of Sciences, Wuhan 430072, P. R. China

${ }^{2}$ Current address: College of Fisheries, Huazhong Agricultural University, Wuhan 430070, P. R. China
\end{abstract}

\begin{abstract}
We reported diel fluctuation in isotopic composition of surface seston from two connected lakes in China, oligotrophic Lake Fuxian and eutrophic Lake Xingyun. The decrease in nighttime and the increase in daytime of isotope signatures of seston might be attributed to the light-dependent balance between the photosynthesis and the respiration of phytoplankton and to the changes in the species composition and the relative abundance of phytoplankton functional groups at the water's surface in diel growth. The relatively high isotopic signatures and the large-extent diel fluctuation of phytoplankton in the eutrophic lake could be due to utilization of heavy-isotope-enriched inorganic sources and the high primary productivity. Extent of diel fluctuation in $\delta^{13} \mathrm{C}$ and $\delta^{15} \mathrm{~N}$ of phytoplankton were relatively small compared with the isotopic enrichment per trophic transfer and thus might have negligible effect on the source identification and the trophic evaluation of consumers.
\end{abstract}

Keywords: stable isotope, diel, phytoplankton, oligotrophic, eutrophic lake

\section{Introduction}

In freshwater ecosystems, phytoplankton is an important constituent to local food webs and the studies on phytoplankton can be helpful to understand the relative importance of this primary producer to the local food webs (Kendall et al. 2001, Lehmann et al. 2004, Xu et al. 2005a, Zeng et al. 2007a,b). Stable isotopic technology is a powerful tool to better understand fate and cycle of carbon and nitrogen of multiple sources in aquatic environments ( $\mathrm{Gu}$ et al. 1996, Post 2002, Lehmann et al. 2004, Gu et al. 2004, Xu et al. 2004). Isotopic signatures of phytoplankton and other sources contribute to identifying sources of organic matter and trophic dynamics in ecosystems (Wada \& Yoshioka 1996, Kendall et al. 2001, Lehmann et al. 2004 Zhang et al. 2007). However, previous studies showed that phytoplankton tend to show greater spatial and temporal variability in isotopic signatures than larger organisms within and between systems ( $\mathrm{Gu}$ et al. 1996, Gu et al. 2004, Xu et al. 2004, Xu et al. 2005a, Gu et al. 2006, Xu et al. 2007a, Zhang et al. 2007). These variations are related to phytoplankton species composition, external nutri-

* Corresponding author: E-mail : xieping@ihb.ac.cn ent input, and primary productivity, as well as sources and concentrations of dissolved inorganic carbon and nitrogen, their isotope signatures, and inherent isotope fractionations and kinetic mode of carbon and nitrogen fixation during photosynthesis (O'Learly 1981, 1989, Falkowski 1991; Grey \& Jones 2001, Gu et al. 2006, $\mathrm{Xu}$ et al. 2007a).

Studies on the diel fluctuation in stable isotope of phytoplankton were rare (Wada \& Yoshioka 1996, Ziegler $\&$ Fogel 2003). The objectives of this investigation was to report diel fluctuation in isotopes composition of phytoplankton from two connected lakes in China (Fig. 1; see details in Xu et al. 2005b, Li et al. 2007, Qin et al. 2007), deep oligotrophic Lake Fuxian and shallow eutrophic Lake Xingyun (see selected limnological parameters in Table 1) and to discuss the preliminary ecological and physiological implications of diel isotopic fluctuation of phytoplankton.

\section{Material and methods}

\section{Sampling}

Lake water for seston was collect from 0 to $0.5 \mathrm{~m}$ water column in 24-26 September, 2003 at the northern 


\section{DIEL ISOTOPIC FLUCTUATION IN SURFACE SESTON}
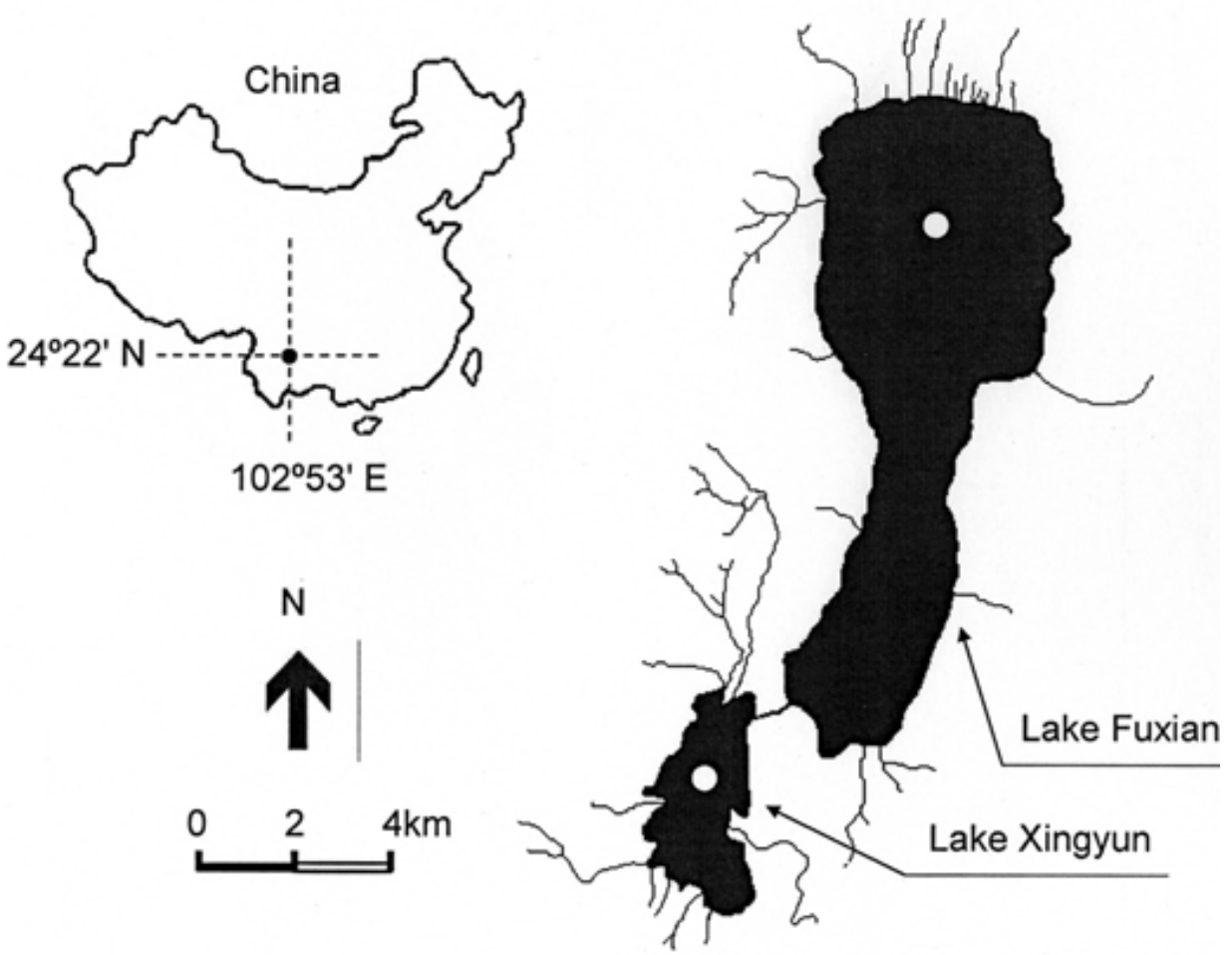

Fig. 1 Map of Lakes Fuxian and Xingyun and the location of sampling sites.

center of Lake Fuxian and the center of Lake Xingyun, and then filtered onto percombusted glass fibre filters (GF/C whatman). The filters (two to three replicates in each site at each time) for isotope analyses were than wrapped in aluminium foil, put into plastic baggies, preserved in an ice box and brought back to laboratory. In the laboratory, the filters, except for nitrogen isotope analysis, were acidified with $1 \mathrm{~N} \mathrm{HCl}$ solution to dissolve possible calcium carbonate $\left(\mathrm{CaCO}_{3}\right)$, followed by a rinse in distilled water, dried to a constant weight at $50^{\circ} \mathrm{C}$ in a drying oven, ground and homogenized to a fine powder with a mortar and pestle, and then stored in a desiccator with a silica gel desiccant for subsequent stable isotope analysis.

\section{Stable isotope analysis}

Stable carbon and nitrogen isotope ratios were analyzed with Delta Plus (Finnigan) continuous flow iso- tope ratio mass spectrometer (CF-IRMS) directly coupled to an NC2500 elemental analyzer (Carlo Erba) for combustion. More than twenty percent of the samples were analyzed two or more times as replicates. Two samples of an internal reference material were analyzed after every five to ten measurements in order to calibrate the system and compensate for drift with time. Isotope ratios were expressed as parts-per-thousand (\%o) differences from a standard reference material using the equation:

$$
\begin{aligned}
& \delta^{13} \mathrm{C}(\%)=\left[\frac{\left({ }^{13} \mathrm{C} /{ }^{12} \mathrm{C}\right)_{\text {sample }}}{\left({ }^{13} \mathrm{C} /{ }^{12} \mathrm{C}\right)_{\text {standard }}}-1\right] \times 10^{3} \\
& \delta^{15} \mathrm{~N}(\%)=\left(\frac{\left({ }^{15} \mathrm{~N} /{ }^{14} \mathrm{~N}\right)_{\text {sample }}}{\left({ }^{15} \mathrm{~N} /{ }^{14} \mathrm{~N}\right)_{\text {standard }}}-1\right] \times 10^{3}
\end{aligned}
$$


Table 1. Average and standard deviation values for selected limnological parameters in Lakes Xingyun and Fuxian.

\begin{tabular}{llllll}
\hline & \multicolumn{2}{c}{ Lake Fuxian } & & \multicolumn{2}{c}{ Lake Xingyun } \\
\cline { 2 - 3 } \cline { 5 - 6 } Parameter & Average & SD & & Average & SD \\
\hline $\begin{array}{l}\text { Total } \\
\begin{array}{l}\text { Nitrogen } \\
\left(\mathrm{mg} \mathrm{L}^{-1}\right)\end{array}\end{array}$ & 0.20 & 0.02 & & 3.21 & 0.33 \\
$\begin{array}{l}\text { Total } \\
\text { Phosphorus } \\
\left(\mathrm{mg} \mathrm{L}^{-1}\right)\end{array}$ & 0.02 & 0.001 & & 0.45 & 0.08 \\
& & & & \\
$\begin{array}{l}\text { Chlorophyll } \\
a\left(\mu \mathrm{g} \mathrm{L}^{-1}\right)\end{array}$ & 1.27 & 0.47 & 280.6 & 97.4 \\
\hline
\end{tabular}

where \%o is parts per thousand and ${ }^{15} \mathrm{~N} /{ }^{14} \mathrm{~N}$ and ${ }^{13} \mathrm{C} /{ }^{12} \mathrm{C}$ are the atomic ratios of the number of atoms in the sample or standard, and $\delta$ is the measure of heavy to light isotope in the sample, whereby higher $\delta$ values denote a greater proportion of the heavy isotope. The standard reference materials were Vienna Pee Dee Belemnite (VPDB) and atmospheric nitrogen for carbon and nitrogen, respectively. International reference materials were IAEA-USGS24 and IAEA-USGS25. The standard deviations of replicate analyses were approximately \pm $0.3 \%$ or for both $\delta^{13} \mathrm{C}$ and $\delta^{15} \mathrm{~N}$.

To examine the differences in isotopic signatures of seston between each sampling time, STATISTIC for Windows statistical software (version 6.0) was used for the relative analyses.

\section{Results and discussion}

Because of the light dependence of assimilation processes of phytoplankton, the diel fluctuation in isotope signatures of phytoplankton from euphotic zone was expected. In this study, the minimal $\delta^{13} \mathrm{C}$ and $\delta^{15} \mathrm{~N}$ of seston were observed at nighttime for both Lake Fuxian $(-29.1 \%$ and $3.5 \%$ ) and Lake Xingyun (-26.5\% and $5.1 \%$ ), while the significant decline in the nighttime was only observed in the eutrophic Lake Xingyun (Fig.
2). The decrease in nighttime might be due to the preferential loss of heavy-isotope-enriched organic matters. For example, extracellular release of assimilated carbon by algae was relatively high and the respiratory losses overnight comprised at least $30 \%$ of the carbon assimilated during the daytime (Tilzer \& Horne 2007), and the carbon isotope fractionation in the carbon metabolism was recognized at the point where acetyl-CoA was divided into two pathways (lipid synthesis and TCA cycle) and the ${ }^{13} \mathrm{C}$-rich acetyl-CoA was introduced into TCA cycle and respired (Wada and Yoshioka 1996). The maximal $\delta^{13} \mathrm{C}$ and $\delta^{15} \mathrm{~N}$ of phytoplankton were observed at daytime for both Lake Fuxian $(-28.4 \%$ and $3.8 \%$ ) and Lake Xingyun (-25.4\%o and 6.7\%o), while the significant increase in the daytime was only observed in the eutrophic Lake Xingyun (Fig. 2). The increase in the $\delta^{13} \mathrm{C}$ and $\delta^{15} \mathrm{~N}$ of phytoplankton in daytime might be due to the active photosynthetic carbon and nitrogen assimilation with relatively small isotope discrimination in the lake water (Kendall et al. 2001, Xu et al. 2005a, $\mathrm{Gu}$ et al. 2006, Xu et al. 2007a). Therefore, these results indicated that the isotope signatures of phytoplankton were partially controlled by the balance between the photosynthesis and the respiration of phytoplankton in diel growth.

There were some alternate mechanisms that could be responsible for the diel isotopic fluctuations in phytoplankton. The diel variation of phytoplankton functional groups in the vertical position was related to light, mixing regime and grazing pressure (Lampert \& Barbara 1985, Yamamoto \& Nakahara 2006, Becker et al. 2008). For example, some phytoplankton species could adjust their buoyancy and might sink rapidly out of the upper water column (Frempong 1981) and some might be preferentially grazed by zooplankton (Lampert \& Barbara 1985) during a diel change. Phytoplankton taxa might vary in their mode and form of nitrogen and carbon acquisition (i.e. $\mathrm{NH}_{4}$ vs. $\mathrm{NO}_{3} ; \mathrm{CO}_{2}$ vs. $\mathrm{HCO}_{3}$ ) and in isotopic fractionations (O'Learly 1981, Falkowski 1991, Goericke et al. 1994, Montoya \& McCarthy 1995, Burkhardt et al. 1999, Joseph et al. 2003) and this could affect isotopic composition of the bulk phytoplankton. Thus, changes in the species composition and the relative abundance of certain groups at the water's surface could cause, to some extent, the diel isotope shifts in phytoplankton.

Diel fluctuations in $\delta^{13} \mathrm{C}$ and $\delta^{15} \mathrm{~N}$ of phytoplankton were summarized in a $\delta^{13} \mathrm{C}-\delta^{15} \mathrm{~N}$ plot (Fig. 3). The average $\delta^{13} \mathrm{C}$ and $\delta^{15} \mathrm{~N}$ of phytoplankton in eutrophic Lake Xingyun were 2.9\%o and 2.2\%o higher than those in oligotrophic Lake Fuxian, and the extent of diel fluctuations in $\delta^{13} \mathrm{C}$ and $\delta^{15} \mathrm{~N}$ were also larger in Lake 

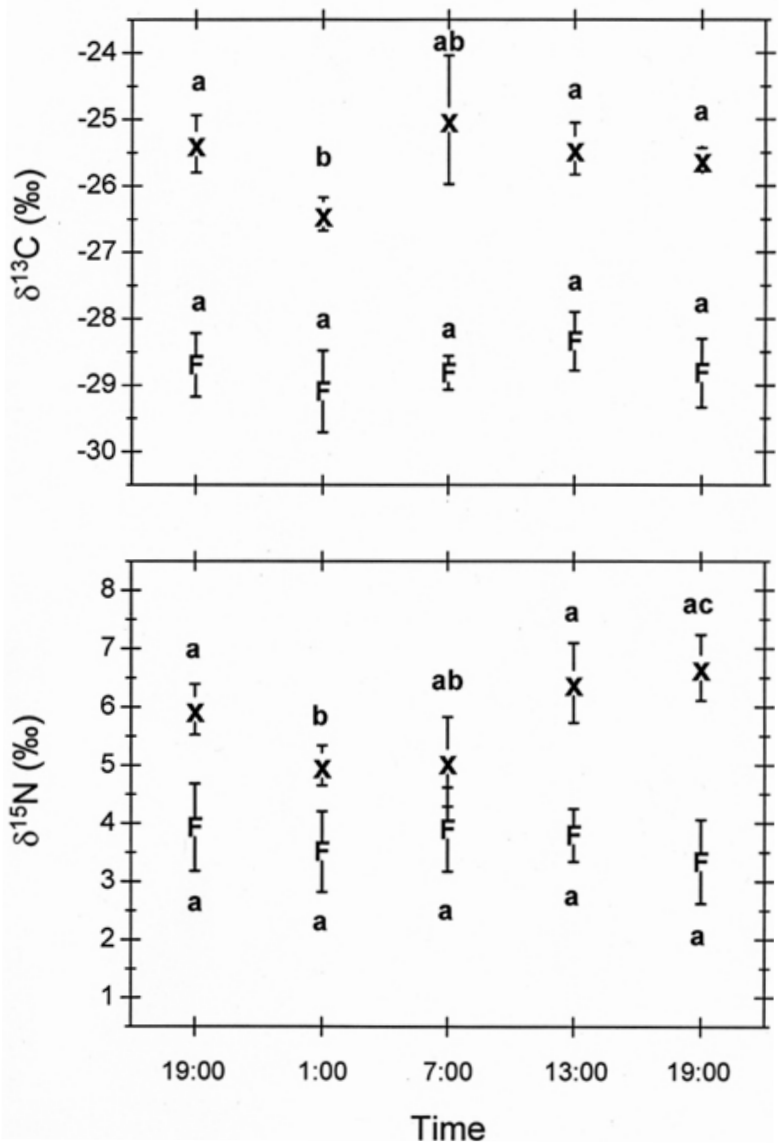

Fig. 2. Diel isotopic fluctuation in stable isotopes of phytoplankton in Lakes Xingyun and Fuxian. Capital letters X and F represent Lake Xingyun and Lake Fuxian, respectively, and the same small letters indicate that there were no significant differences in isotopic signatures among the sampling times at p-level $<0.05$.

Xingyun compared with those in Lake Fuxian (Fig. 3). Lake Xingyun provided ${ }^{13} \mathrm{C}$ and ${ }^{15} \mathrm{~N}$ enriched inorganic sources concomitant with eutrophication to phytoplankton, and primary production rate of phytoplankton in Lake Xingyun was 4-5 times higher than that of Lake Fuxian (Xu et al. 2005b). Thus, the relatively high isotopic signatures and the large-extent diel fluctuation of phytoplankton in Lake Xingyun might be due to that phytoplankton in Lake Xingyun utilized heavy-isotopeenriched inorganic sources and growth at high produc-

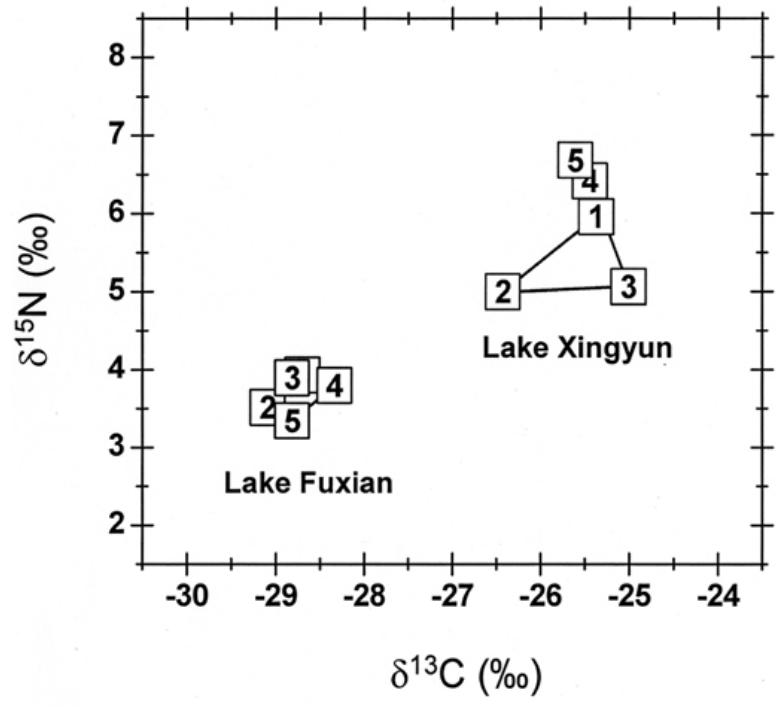

Fig. 3. $\delta^{13} \mathrm{C}$ vs. $\delta^{15} \mathrm{~N}$ plot for the diel fluctuation of phytoplankton in Lakes Xingyun and Fuxian. Numbers in the boxes on the graph represents each sampling time $(1,19: 00 ; 2,1: 00 ; 3,7: 00 ; 4,13: 00$; $5,19: 00)$ and each point represents the mean value of isotope ratios with error bars around the mean omitted for simplicity.

tivity because of the eutrophication (Gu et al. 2004, Xu et al. 2005b, Gu et al. 2006).

Generally, in the use of stable isotopic technique to study trophic relationship, $\delta^{13} \mathrm{C}$ and $\delta^{15} \mathrm{~N}$ showed $1 \%$ and $3.4 \%$ per trophic level enrichment, respectively (DeNiro \& Epstein 1978, Minagawa \& Wada 1984, Post 2002, Xu et al. 2007b). In this study, extent of diel fluctuation in averaged $\delta^{13} \mathrm{C}$ and $\delta^{15} \mathrm{~N}$ of phytoplankton were relatively small (within 1\%o) compared with the isotopic enrichment per trophic transfer and thus might have negligible effect on the identification of the importance of phytoplankton and other different sources of primary production to consumers higher up the food chain (France 1995, Vander Zanden \& Vadeboncoeur 2002, Xu \& Xie 2004, Xu et al. 2007b).

The short sampling regime and the lack of information about the diel vertical changes in taxonomic composition of phytoplankton would bias the diel patterns in isotopic signature of phytoplankton and the corresponding speculation in this study. Further researches 
on the diel variations in the taxonomic composition and abundance of phytoplankton functional groups and in water chemistry and isotopic composition of dissolved species of nitrogen and carbon would be far more comprehensive and of ecological relevance to clarify the mechanisms of the diel fluctuation in phytoplankton isotopic compositions.

\section{Acknowledgement}

This research was supported by a key project of the Chinese Academy of Sciences (Grant No. KZCX1-SW-13).

\section{References}

Becker V., de Souza Cardos L. \& Huszar V.L.M. 2008. - Diel variation of phytoplankton functional groups in a subtropical reservoir in southern Brazil during an autumnal stratification period. Aquat. Ecol., 10.1007/s10452-008-9164-0.

Burkhardt S., Riebesell U. \& Zondervan I. 1999. - Stable carbon isotope fractionation by marine phytoplankton in response to daylength, growth rate, and $\mathrm{CO}_{2}$ availability. Mar. Ecol. Prog. Ser., $184,31-41$

DeNiro M.J. \& Epstein S. 1978. - Influence of diet on the distribution of carbon isotopes in animals. Geochim. Cosmochim. Acta, 42, 495-506.

Falkowski P.G. 1991. - Species variability in the fractionation of ${ }^{13} \mathrm{C}$ and ${ }^{12} \mathrm{C}$ by marine phytoplankton. J. Plankton Res., 13, 21-28.

France R.L. 1995. - Differentiation between littoral and pelagic food webs in lakes using stable carbon isotopes. Limnol. Oceanogr., 40, $1310-1313$

Frempong E. 1981. - Diel variation in the abundance, vertical distribution, and species composition of phytoplankton in a eutrophic english lake. J. Ecol., 69, 919-939.

Goericke R., Montoya J.P. \& Fry B. 1994. - Physiology of isotopic fractionation in algae and cyanobacteria. Pages 187-221 in Stable isotopes in ecology and environmental science. Lajtha K. \& Michener R.H. (eds) Blackwell Scientific Publications, Oxford.

Grey J. \& Jones R.I. 2001. - Seasonal changes in the importance of the source of organic matter to the diet of zooplankton in Loch Ness, as indicated by stable isotope analysis. Limnol. Oceanogr., 46, 505-513.

Gu B., Chapman A.D. \& Schelske C.L. 2006. - Factors controlling seasonal variations in stable isotope composition of particulate organic matter in a soft water eutrophic lake. Limnol. Oceanogr., 51, 2837-2848.

Gu B. \& Schelske C.L. 1996. - Temporal and spatial variations in phytoplankton carbon isotopes in a polymictic subtropical lake. J. Plankton Res., 18, 2081-2092.

Gu B. \& Schelske C.L. 2004. - Extreme ${ }^{13} \mathrm{C}$ enrichments in a shallow hypereutrophic lake: Implications for carboncycling. Limnol. Oceanogr., 49, 1152-1159.

Joseph A.N., Waser N.A., Harrison P.J. \& Calvert S.E. 2003. - Nitrogen isotope fractionation in 12 species of marine phytoplankton during growth on nitrate. Mar. ecol. Prog. Ser., 255, 81-91.

Kendall C., Silva S.R. \& Kelly V.J. 2001. - Carbon and nitrogen isotopic compositions of particulate organic matter in four large river systems across the United States. Hydrol. Process., 15, 1301-1346.

Lampert W. \& Barbara E. 1985. - Zooplankton Grazing in a Eutrophic Lake: Implications of Diel Vertical Migration. Ecology, 66, 68-82.

Lehmann M.F., Bernasconi S.M., Mckenzie J.A., Barbieri A., Simona
M. \& Veronesi M. 2004. - Seasonal variation of the $\delta^{13} \mathrm{C}$ and $\delta^{15} \mathrm{~N}$ of particulate and dissolved carbon and nitrogen in Lake Lugano: Constraints on biogeochemical cycling in a eutrophic lake. Limnol. Oceanogr., 49, 415-429.

Li S., Xie P., Xu J., Li L., Zhang X., Qin J., Zheng L. \& Liang. G. 2007. - Factors Shaping the Pattern of Seasonal Variations of Microcystins in Lake Xingyun, a Subtropical Plateau Lake in China. B. Environ. Contamin. Tox., 78, 226-230.

Minagawa M. \& Wada E. 1984. - Stepwise enrichment of ${ }^{15} \mathrm{~N}$ along food chains: Further evidence and the relation between ${ }^{15} \mathrm{~N}$ and animal age. Geochim. Cosmochim. Acta, 48, 1135-1140.

Montoya J.P. \& McCarthy J.J. 1995. - Isotopic fractionation during nitrate uptake by phytoplankton grown in continuous culture. J. Plankton Res., 17, 439-464.

O'Leary M. 1981. - Carbon isotope fractionation in plants. Phytochemistry, 28, 553-567.

Post D.M. 2002. - Using stable isotopes to estimate trophic position: models, methods, and assumptions. Ecology, 83, 703-718.

Qin J., Xu J. \& Xie P. 2007. - Diet overlap between the endemic fish Anabarilius grahami (Cyprinidae) and the exotic noodlefish $\mathrm{Neo}$ salanx taihuensis (Salangidae) in Lake Fuxian, China. J. Freshw. Ecol., 22, 365-370.

Tilzer M.M. \& Horne A.J. 2007. - Diel patterns of phytoplankton Productivity and extracellular release in ultra-oligotrophic Lake Tahoe. Internationale Revue der gesamten Hydrobiologie und Hydrographie, 64, 157-176.

Vander Zanden M. J. \& Vadeboncoeur Y. 2002. - Fishes as integrators of benthic and pelagic food webs in lakes. Ecology, 83, 2152-2161.

Wada E. \& Yoshioka T. 1996. - Isotope biogeochemistry of several aquatic ecosystem. Geochem. International, 33, 287-307.

Xu J. \& Xie P. 2004. - Studies on the food web structure of Lake Donghu using stable carbon and nitrogen isotope ratios. J. Freshw. Ecol., 19, 645-650.

Xu J., Li S. \& Xie P. 2005b. - Differences in $\delta^{13} \mathrm{C}$ and $\delta^{15} \mathrm{~N}$ of particulate organic matter from the deep oligotrophic Lake Fuxian connected with the shallow eutrophic Lake Xingyun, China. $B$. Environ. Contamin. Tox., 74, 281-285.

Xu J., Xie P., Zhang M. \& Yang H. 2005a. - Variation in stable isotope signatures of seston and a zooplanktivorous fish in a eutrophic Chinese lake. Hydrobiologia, 541, 215-220.

Xu J., Zhang M. \& Xie P. 2007a. - Stable carbon isotope variations in surface bloom scum and subsurface seston among shallow eutrophic lakes. Harmful Algae, 6, 679-685.

Xu J., Zhang M. \& Xie P. 2007b. Size-related shifts in reliance on benthic and pelagic food webs by lake anchovy. Ecoscience, 14, 170-177.

Yamamoto Y. \& Nakahara H. 2006. - Seasonal variations in the diel vertical distribution of phytoplankton and zooplankton in a shallow pond. Phycol. Res., 54, 280-293.

Zeng Q., Kong F., Zhang E., Tan X. \&Wu X. 2007a. - Seasonality of stable carbon and nitrogen isotopes within the pelagic food web of Taihu Lake. Ann. Limnol. - Int. J. Lim., 28, 55-60.

Zeng Q., Kong F., Zhang E., Wu X. \& Tan X. 2007b. - Stable isotope analyses of size-based microplankton trophic structure in Taihu Lake during a cyanobacterial bloom. J. Freshw. Ecol., 22, 553-559.

Zhang L., Xu J., Xie P., Zang X., Qiu G. \& Zeng J. 2007. - Stable isotope variations in particulate organic matter and a planktivorous fish in the Yangtze River. J. Freshw. Ecol., 22, 383-386.

Ziegler S.E. \& Fogel M.L. 2003. - Seasonal and diel relationships between the isotopic compositions of dissolved and particulate organic matter in freshwater ecosystems. Biogeochemistry, 64, $25-52$. 
